\title{
Microstructure and residual stresses of laser structured surfaces
}

\author{
Johannes Preußner ${ }^{1 a^{*}}$, Sabine Oeser ${ }^{1}$, Wulf Pfeiffer ${ }^{1}$, André Temmler ${ }^{2}$, \\ Edgar Willenborg ${ }^{3}$ \\ ${ }^{1}$ Fraunhofer IWM, Wöhlerstraße 11, 79108 Freiburg im Breisgau, Freiburg, Germany \\ ${ }^{2}$ RWTH Aachen University, Steinbachstr. 15, 52074 Aachen, Germany \\ ${ }^{3}$ Fraunhofer-Institute for Lasertechnology ILT, Steinbachstr. 15, 52074 Aachen, Germany \\ a johannes.preussner@iwm.fraunhofer.de
}

Keywords: microscopy, X-ray diffraction, steel, microstructure, structuring by laser remelting

\begin{abstract}
.
A new approach to structure metallic surfaces with laser radiation is structuring by remelting. In this process no material is removed but reallocated by melting. The laser power was adapted linearly to the increasing laser beam diameter for laser remelted (polished) samples. A carbon depleted area could be found close to the remelted zone accompanied with a local minimum in hardness. The surface residual stresses tend from tensile to compressive with increasing laser beam diameter/laser power and number of repetitions for laser structured and laser remelted samples. The residual stresses are a result of combined shrinkage (tensile) and transformation (compressive) stresses.
\end{abstract}

\section{Introduction}

Properties and functions like abrasion and corrosion resistance, haptics and the visual impression of a part are strongly influenced by its surface. Therefore, many parts have structured surfaces that are wavy or serrated. Special textures are often used, like leather or textile surfaces. Grips and handles are fluted to prevent slipping.

Structured polymer parts can be manufactured by the injection moulding process. There, in order to achieve specific surface topographies, the mould surface is structured by photochemical etching, which is a time consuming and expensive process. Large amounts of acids are used, resulting in a great potential for harming the environment if the remaining acids were not disposed properly. A totally new approach is structuring metallic surfaces with laser radiation by remelting. In this process no material is removed but reallocated in the liquid phase. The innovation of structuring by remelting is a totally new active principle (remelting) in comparison to the conventional structuring by photochemical etching or structuring by laser ablation (removal). In this new process, the surface structure and the micro roughness result from a laser-controlled self-organisation of the melt pool due to surface tension. The process of structuring by laser remelting is similar to polishing by remelting [1]. The structuring process is described in detail in Temmler et al. [2]. During the process, the melt pool volume can be precisely modulated by adding an additional periodic laser power with the amplitude $\mathrm{P}_{\mathrm{A}}$ and a wavelength $\lambda$ to the average laser power $\mathrm{P}_{\mathrm{M}}$ while the laser beam is moved over the surface by a $2 \mathrm{D}$ laser scanner with a defined scanning velocity and track offset.

The process of structuring by laser remelting is based on the physical interaction between the variation of the melt pool volume and the movement of the three-phase line. This movement determines the resulting surface topography. The wavelength $\lambda$ of the laser power modulation is equivalent to the wavelength of the remelted structures. Naturally, the surface properties of metals change when using a laser remelting process. These changes in properties and microstructure are discussed in the paper. 


\section{Experimental}

Laser remelted and laser structured surfaces are produced of a hot work tool steel 1.2343 using a fibre-coupled, Q-switched, Nd:YAG, solid state laser with an emitting wavelength $\lambda$ em. of $1064 \mathrm{~nm}$ and a maximum output laser power $P_{\mathrm{L}, \max }$ of $400 \mathrm{~W}$. The device is equipped with motorized apertures and a zoom telescope which allow to alter the laser beam diameter continuously in the range of $d_{\mathrm{L}}=125 \mu \mathrm{m}$ up to $d_{\mathrm{L}}=800 \mu \mathrm{m}$. A 3D laser scanning system enables fast, threedimensional deflection of the focused laser beam on the work-piece surface. The setup is described in detail in $[3,4,5]$. The principle of the process is shown in Fig. 1a. The process parameters of the laser remelted samples that were used for the experimental investigation are summarized in Table 1.

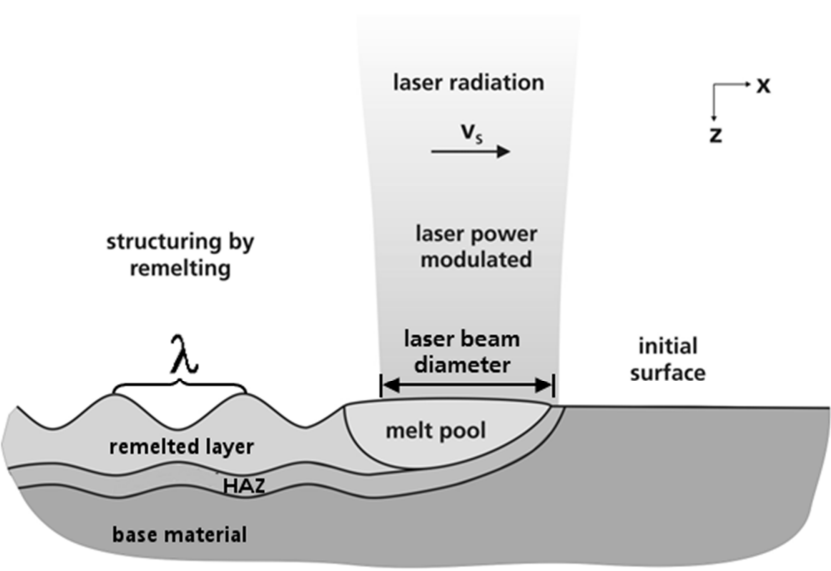

a)
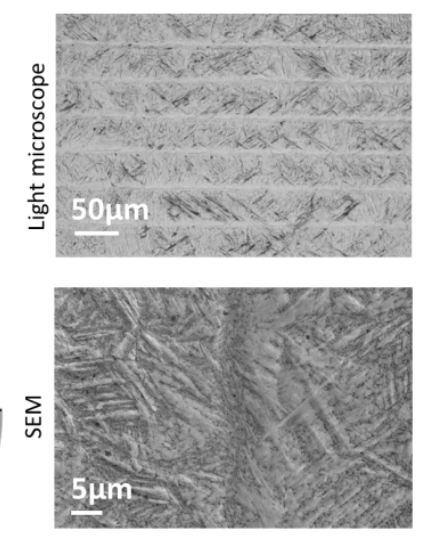

Laser remelted sample 2-4
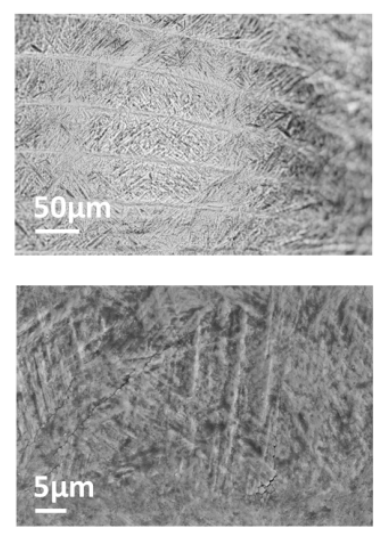

Laser structured sample Struc1

b)

Fig. 1: a) Sketch of a cross-section of a bulk metallic material during the structuring process. A thin surface layer is remelted. A modulated laser power results in a structured surface. b) Images of the surfaces of a laser remelted (left) and laser structured (right) samples taken with the light microscope and the scanning electron microscope (SEM).

The samples are numbered as shown in the first column of Table 1 plus the number of repetitions (i.e. remelting steps). The caption "Sample 1-4" describes a sample processed with $\mathrm{P}_{\mathrm{L}}=65 \mathrm{~W}$ $\left(d_{L}=150 \mu \mathrm{m}\right)$ and 4 repetitions. The consecutive remelting steps are executed perpendicular to each other, alternating at $0^{\circ}$ and $90^{\circ}$. The orientation of the residual stress measurements are given with respect to the last laser track, i.e. stress component parallel to the orientation of the last laser track.

Table 1: Parameters of laser remelted samples (without structuring)

\begin{tabular}{|l|l|l|l|l|l|l|}
\hline sample & $\begin{array}{l}\text { laser } \\
\text { power } P_{\mathrm{L}} \\
(\mathrm{W})\end{array}$ & $\begin{array}{l}\text { scanning } \\
\text { velocity } v_{\mathrm{s}} \\
\left(\mathrm{ms}^{-1}\right)\end{array}$ & $\begin{array}{l}\text { track } \\
\text { offset } d y \\
(\mu \mathrm{m})\end{array}$ & $\begin{array}{l}\text { laser beam } \\
\text { diameter } \\
d_{\mathrm{L}}(\mu \mathrm{m})\end{array}$ & $\begin{array}{l}\text { number of } \\
\text { repetitions } \\
X\end{array}$ & $\begin{array}{l}\text { Laser } \\
\text { power/area } \\
\left(\mathrm{mW} / \mu \mathrm{m}^{2}\right)\end{array}$ \\
\hline $1-X$ & 65 & 0.1 & 25 & 150 & $1 ; 2 ; 4 ; 8 ; 16$ & 3.68 \\
\hline $2-X$ & 100 & 0.1 & 40 & 250 & $1 ; 2 ; 4 ; 8 ; 16$ & 2.04 \\
\hline $3-X$ & 150 & 0.1 & 65 & 380 & $1 ; 2 ; 4 ; 8 ; 16$ & 1.32 \\
\hline $4-X$ & 240 & 0.1 & 100 & 600 & $1 ; 2 ; 4 ; 8 ; 16$ & 0.85 \\
\hline $5-X$ & 320 & 0.1 & 130 & 800 & $1 ; 2 ; 4 ; 8 ; 16$ & 0.64 \\
\hline
\end{tabular}

In order to achieve periodic structures the laser power is modulated sinusoidally at the average laser power $\mathrm{P}_{\mathrm{M}}$ with an amplitude of $\mathrm{P}_{\mathrm{A}}$ (Peak-Valley-Value) and a wavelength $\lambda$. The process parameters used for the structured samples are shown in Table 2 
Table 2: Parameters of laser structured samples

\begin{tabular}{|l|l|l|l|l|l|l|l|}
\hline sample & $\begin{array}{l}\text { average } \\
\text { laser power } \\
\mathrm{P}_{\mathrm{M}}(\mathrm{W})\end{array}$ & $\begin{array}{l}\text { amplitude } \\
\text { of laser } \\
\text { power } \mathrm{P}_{\mathrm{A}} \\
(\mathrm{W})\end{array}$ & $\begin{array}{l}\text { scanning } \\
\text { velocity } \mathrm{v}_{\mathrm{s}}\end{array}$ & $\begin{array}{l}\text { track offset } \\
\mathrm{dy}(\mu \mathrm{m})\end{array}$ & $\begin{array}{l}\text { laser beam } \\
\text { diameter } \\
\mathrm{d}_{\mathrm{L}}(\mu \mathrm{m})\end{array}$ & $\begin{array}{l}\text { number of } \\
\text { repetitions } \\
\mathrm{X}\end{array}$ & $\begin{array}{l}\text { Wavelength } \\
\lambda\end{array}$ \\
\hline Struc1 & 115 & 50 & 0,05 & 50 & 250 & 4 & 4 \\
\hline Struc2 & 305 & 100 & 0,05 & 150 & 600 & 4 & 3 \\
\hline Struc3 & 305 & 100 & 0,05 & 150 & 600 & 16 & 3 \\
\hline
\end{tabular}

Residual stresses are measured with a D8 Advance (Bruker AXS) and a D5000 (Siemens) X-ray diffractometer with an open Eulerian cradle and a $\mathrm{Cr}$-Anode $\left(\mathrm{K}_{\alpha}\right.$-wavelength approx. $0.23 \mathrm{~nm}$, effective penetration depth approx. $5 \mu \mathrm{m}$, diameter of the X-ray beam approx. $0.8-1.0 \mathrm{~mm}$ ). The location of the diffraction peaks are acquired by fitting a pseudo-Voigt-function to the diffraction data. Residual stresses were evaluated using the $\sin ^{2} \psi$-method [6,7]. The error bars of the measurements result from the errors in the determination of the slopes of the regression lines of the $\sin ^{2} \psi$-distribution. A scanning electron microscope (SEM) Zeiss Supra $40 \mathrm{VP}$ with acceleration voltage of $20 \mathrm{kV}$ is used for observation of the samples. Depth profiles of the chemical composition of the samples are measured with a GDS 850A glow discharge spectrometer from Leco. Hardness profiles are measured on metallographic cross sections with a Fischerscope H100CXYp and a force of $20 \mathrm{mN}$ approached at $20 \mathrm{~s}$ and a holding time of $10 \mathrm{~s}$. The Vickers hardness HV is calculated from $\mathrm{H}_{\text {IT }}$ [8], which results in Vickers hardness numbers of approx. HV0.002.

\section{Results}

From a metallurgical point of view laser structuring, like welding, equals a local remelting and a heat treatment with rapid heating and cooling and a very short dwell time. Usually temperature gradients of $\sim 10^{6}-10^{7} \mathrm{~K} / \mathrm{s}$ can be achieved. This results in a surface hardening. Whereas along laser remelted samples or along a casual laser weld seam the power of the laser beam is kept constant, this laser power is modulated during the laser structuring process resulting in a more complex temperature-time-characteristic at the seam.

Assessment of structured surfaces Fig. 1b shows sample surfaces of laser remelted samples produced without a modulation of the laser power, resulting in a smooth surface (left) and a sample where the laser power has been modulated (right). Martensite needles can be seen at the sample surfaces of structured and polished samples resulting from the rapid cooling of the hot work steel 1.2343 .

Residual stresses via XRD. When large temperature gradients and heating/cooling rates occur, residual stresses develop in the material due to thermal expansion/shrinkage, the temperature dependent plastic flow behaviour of the material and phase transformations. Near-surface residual stress measurements were performed on laser remelted and laser structured samples. The topography of structured samples reduces the accuracy of the measurement. As shown in figure Fig. 2a, the residual stresses are strongly influenced by the process parameters. 


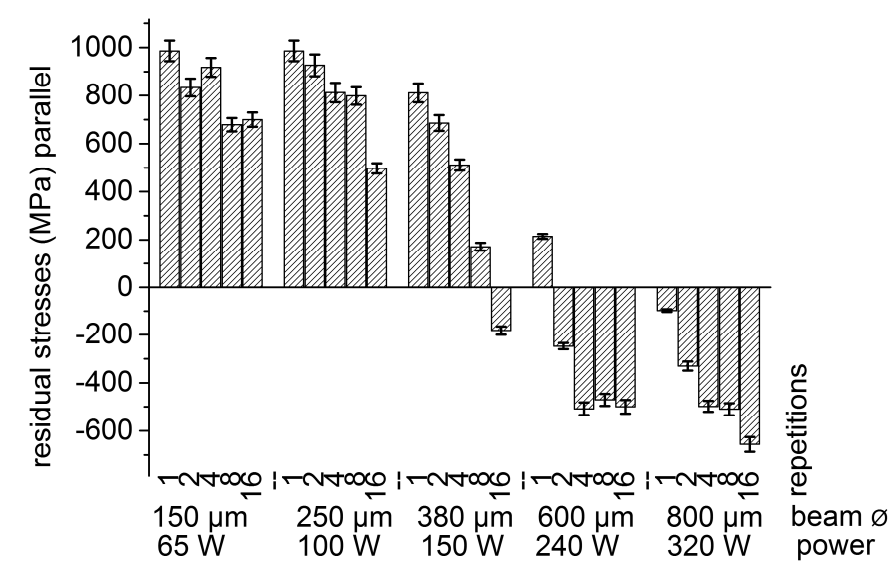

a)

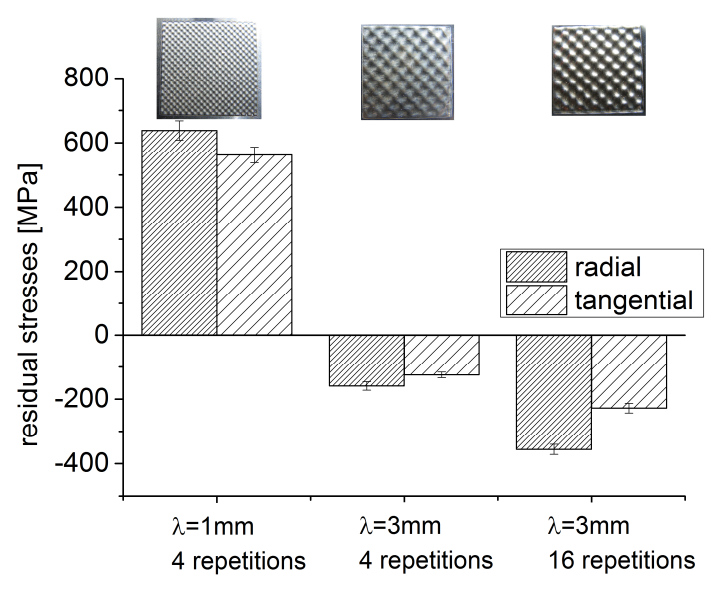

b)

Fig. 2: a) Correlation between different process parameters (laser beam diameter, laser power and number of repetitions) on the residual stresses at laser remelted samples, processed with constant laser power. The stress component parallel to the last laser track is shown here [9]. b) The residual stresses of different laser-structured samples produced with modulated laser power. The correlation of residual stresses to chosen process parameters wavelength $\lambda$ and number of repetitions are shown in the graph. Macro pictures of structured surfaces are shown above the graphs.

The surface layers produced with small laser beam diameters, i.e. small remelted volumes, show significant tensile stresses due to the solidification and cooling process. The amount of these stresses decrease with increasing laser beam diameter and with increasing number of repetitions. The stress component tangential to the last laser track show a similar tendency (not shown here). At larger beam diameters $\left(\mathrm{d}_{\mathrm{L}}=600,800 \mu \mathrm{m}\right)$ the residual stress state changes from tensile to compressive. This characteristic is similar to laser structured samples. At smaller structure wavelengths, like $1 \mathrm{~mm}$, the laser beam diameter was chosen to $250 \mu \mathrm{m}$ and the average laser power is adapted to $115 \mathrm{~W}$. At the structured surface tensile stresses occur as can be seen in Fig. $2 \mathrm{~b}$. At larger wavelengths, like $3 \mathrm{~mm}$, the laser beam diameter and the mean laser power is higher and compressive stresses occur. These compressive stresses rise when multiple remelting is applied, as observed in the laser polished samples.

Analysis of microstructure, chemical composition and micro-hardness. Metallographic crosssections are prepared from selected samples for microstructural characterisation and (nano-) hardness measurements. The depths of the remelted layers ranges from $33 \mu \mathrm{m}\left(\mathrm{d}_{\mathrm{L}}=150 \mu \mathrm{m} / 1\right.$ repetition) to $82 \mu \mathrm{m}\left(\mathrm{d}_{\mathrm{L}}=800 \mu \mathrm{m} / 16\right.$ repetitions $)$.

Concentration- depth profiles of carbon and other alloying elements are shown inFig. 3a. A local minimum of carbon can be found for the samples at the end of the remelted layer (transition to the heat affected zone). This carbon depletion leads to a small local hardness minimum in that region. The peak of local decarburization is more pronounced with increasing number of repetitions, see [9].

Hardness maps of samples with varying process parameters have been measured, i.e. Fig. 3b. Both the depth of the remelted zone and the heat affected zone increase with increasing wavelength. The increase in wavelength comes along with an increase in average laser power and laser beam diameter. The surface hardness increases with number of repetitions. In hardness maps the local decrease of hardness due to the carbon depletion can be seen (see Fig. $3 \mathrm{~b}$ with $\lambda=3 \mathrm{~mm}, 16$ repetitions). 


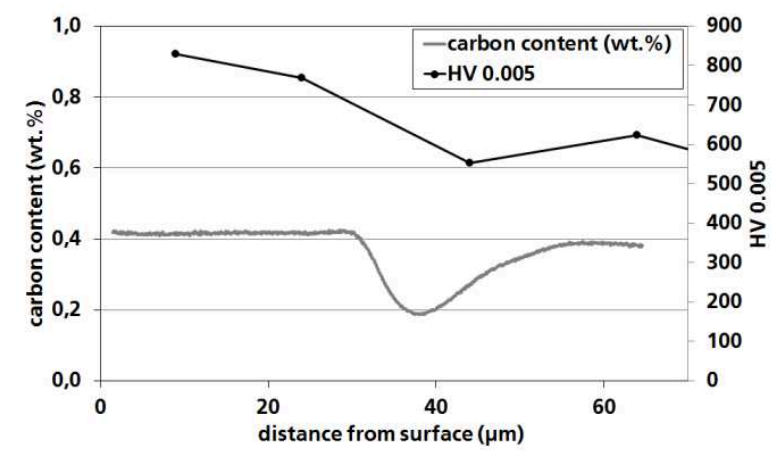

a)

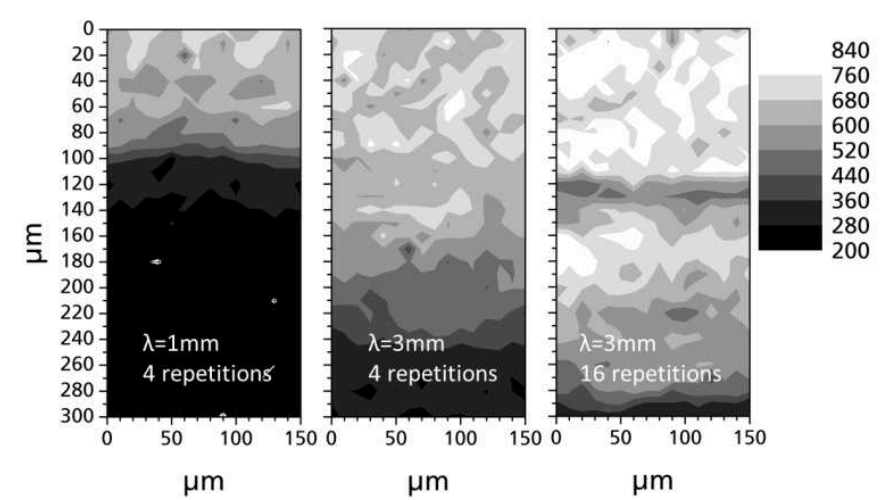

b)

Fig. 3: a) Measured carbon content and hardness with distance from surface for the laser remelted sample 2-16. B) Mappings of the micro hardness $\mathrm{HVO.002}$ (calculated from $\mathrm{H}_{\mathrm{IT}}$ ) of various structured samples. The hardness measurements are measured on the peaks of the structured samples.

\section{Discussion}

The depletion of carbon, see Fig. 3a, can be explained by a higher solubility of carbon in the melt pool than in the solid fraction. During melting carbon diffuses from the solid fraction to the melt pool and remains there. Indeed a slightly higher amount of carbon in the solidified layer compared to the base material can be found, see Fig. 3a. It is also possible that a certain amount of carbon goes into the gas phase with the presence of oxygen in the process gas. The carbon depletion comes along with a minimum in hardness, see Fig. 3a and b, as carbon is the major hardening element in steel.

During cooling, shrinkage of the material occurs due to the thermal contraction. In a constrained specimen, i.e. a relatively large specimen that is locally remelted in a welding process, tensile stresses in the welded zone appear. When the yield strength is reached, plastic flow occurs and the tensile stresses will be reduced. The martensitic phase requires a higher volume than the face centered cubic austenitic phase. Both the martensitic transformation and the plasticity during rapid cooling in a constrained sample relieves the tensile residual stresses (compared with slow cooling and formation of ferrite/pearlite) and can even lead to compressive stresses. The different contributions of shrinkage, plastic flow and phase transformation on residual stress contribute to the final residual surface stresses. The laser structured and laser polished samples show the same trend to reduced tensile surface residual stresses with increasing laser beam diameter and laser power, which is partially related to the size of the melt pool. Larger melt pools decrease the temperature gradient and therefore decrease the stress gradient between melt and the surrounding material. This leads to a reduced tensile residual stresses related to hindered shrinkage because the volumetric expansion associated with martensite formation becomes more relevant. When using multiple repetitions, the sample itself heats up, resulting in a preheating effect, see also [9]. In Fig. 2a and b the tendency towards near-surface compressive stresses can be seen with increasing laser beam diameter and increasing number of repetitions for laser polished and laser structured samples.

\section{Conclusion}

The influence of varying process parameters of laser remelted and laser structured samples on the microstructure and residual stresses in the affected surface layers have been analyzed. In this study the irradiated energy per area was kept constant. The laser power was adapted linearly to the increasing laser beam diameter for laser remelted (polished) samples.

A carbon depleted area could be found close to the remelted zone accompanied with a local minimum in hardness. The surface residual stresses tend from tensile to compressive with 
increasing laser beam diameter/laser power for laser structured and laser remelted samples. The formation of surface residual stresses is explained by a combination of shrinkage (tensile) stresses and transformation (compressive) stresses. The residual stresses tend from tensile to compressive with increasing number of repetitions which can be explained by a preheating effect.

\section{Acknowledgements:}

The authors like to thank the Volkswagen Stiftung for financial support of the Funding Initiative I / 83252 with the project title »Process and machine technology for structuring of design surfaces by laser remelting (FluidStruc)《. The laser remelted samples were partially produced or quality checked with facilities and devices funded by the Federal State of North-Rhine Westphalia within the center for nanophotonics under grant number 290047022.

\section{References}

[1] Ostholt, R., Willenborg, E., Wissenbach, K. Laser polishing of metallic freeform surfaces Ostendorf, A.: Lasers in Manufacturing 2009: Proceedings of the $5^{\text {th }}$ International WLTConference, LiM 2009, AT-Fachverlag, 2009, pp. 397-401

[2] Pirch, N., Höges, S. and Wissenbach, K. 2006. Mechanisms of surface rippling during laser polishing. Proceedings of the $8^{\text {th }}$ International Seminar on Numerical Analysis of Weldability. Graz-Seggau: 2006. pp. 25-27

[3] A. Temmler, E. Willenborg, K. Wissenbach, Design Surfaces by Laser Remelting, Physics Procedia Lasers in Manufacturing 2011 - Proceedings of the $6^{\text {th }}$ International WLT Conference on Lasers in Manufacturing, 2011, 12, Part A, 419-430

[4] A. Temmler, E. Willenborg, K. Wissenbach, Proceedings of the $7^{\text {th }}$ International Conference on MicroManufacturing: (ICOMM 2012); Evanston, IL, 2012, S. 298-305

[5] Kiedrowski T.; Willenborg E.; Hack, S.; Wissenbach K.: Generation of design structures by selective polishing of metals with laser radiation - Proceedings of the $3^{\text {rd }}$ Int. WLT-Conference on Lasers in Manufacturing 2005, Munich, June 2005

[6] European Standard EN 15305:2008

[7] E. Macherauch, P. Müller: Z. Angew. Phys. XIII (1961) 305-312.

[8] according to EN ISO 14577-1:2002

[9] J. Preußner, S. Oeser, W. Pfeiffer, A. Temmler, E. Willenborg, Int. J. Mater. Res., accepted for publication on Nov 15, 201, DOI: 10.3139/146.111027 